\title{
The Critical Need to Diversify the Clinical and Academic Workforce
}

\author{
Laura Weiss Roberts • Yvonne Maldonado • \\ John H. Coverdale • Richard Balon • Alan K. Louie • \\ Eugene V. Beresin
}

Received: 27 May 2014 / Accepted: 28 May 2014 / Published online: 3 July 2014

(C) Academic Psychiatry 2014

Only a small proportion of faculty in the medical schools of the USA reflects racial and ethnic minority groups, according to the Association of American Medical Colleges [1]. In 2010, $8 \%$ of faculty were underrepresented minority individuals, defined as self-reported Black/African American, Hispanic/ Latino, Native American, Alaskan Native, Native Hawaiian, or Pacific Islanders [1, 2]. According to the US Census, in the same year, $17 \%$ of the population self-identified as Hispanic/ Latino [3] and $13 \%$ as Black/African American [4], with both groups growing more rapidly ( $43 \%$ and $15 \%$, respectively) than the average growth rate of $9.7 \%$ from 2000 to 2010 [3, 4]. People of racial and ethnic minority backgrounds are expected to make up more than half of the population by 2060 per population projections from the 2010 census [5].

These data regarding underrepresentation of racial and ethnic minority groups in medicine have important public health implications. There is evidence that ethnic minority physicians are more likely to provide care for ethnic minority and socioeconomically disadvantaged patients [6]. There is also a link between race and ethnic concordance of physicians and patients and the quality of patient-physician communication, other health care processes, and some patient outcomes [6]. In one study, patients with providers from the same racial backgrounds were more satisfied and rated their physicians as more engaged and participatory than those with providers

L. W. Roberts $(\bowtie) \cdot$ Y. Maldonado $\cdot$ A. K. Louie

Stanford University School of Medicine, Stanford, CA, USA

e-mail: RobertsL@stanford.edu

J. H. Coverdale

Baylor College of Medicine, Houston, TX, USA

R. Balon

Wayne State University, Detroit, MI, USA

E. V. Beresin

Harvard Medical School, Boston, MA, USA from different racial groups [7]. It has also been suggested that physicians' unconscious biases may contribute to racial and ethnic disparities in the use of medical procedures such as thrombolysis for myocardial infarction [8].

Women are on the way to greater representation in medicine. At this time, approximately $70 \%$ of the overall physician workforce is male [9]. Women are most highly represented in pediatrics (58\%), internal medicine/pediatrics (50\%), child and adolescent psychiatry (48\%), obstetrics and gynecology (47\%), and geriatric medicine (47\%). Looking ahead, nearly half ( $46 \%$ ) of residents and fellows in programs accredited by the Accreditation Council for Graduate Medical Education are female [2]. Two-thirds or more of residents are women in several fields, including obstetrics and gynecology (81\%); pediatrics (73\%); endocrine, diabetes, and metabolism (67\%); and rheumatology (66\%). Nearly $62 \%$ of the 838 total residents and fellows in child and adolescent psychiatry are women, and $55 \%$ of the 4,947 total psychiatry residents are women. Women will have greater presence in absolute numbers and in proportion in the physician workforce of the future; primary care and "cognitive" specialties, rather than procedural specialties except obstetrics, will have greater representation of women relative to other fields.

\section{On the Path to Medicine}

So how does the pattern of some groups being more highly represented and others being less well represented in medicine emerge? Comparisons of data drawn at three points along the path to physicianhood help us to discern when it is that some young people lose their dream-while others become inspired-to become a doctor. In a highly robust 2002 AAMC report involving a nationally representative sample of 15,362 high school sophomores, $24 \%$ of physician-aspiring students are 
Hispanic [10]. Data from US medical schools indicate that only $7 \%$ of applicants and matriculants are Hispanic. In this same study, $18 \%$ of physician-aspiring students are black, while only $7 \%$ of medical school applicants are black. Three quarters of the sophomore girls aspired to become a physician, and about half of the pools of applicants and matriculants now are women. The profession of medicine appears to lose young women and underrepresented minority students during a critical five- or six-year period in their lives - at the end of high school and the beginning of college.

In contrast, disproportionate numbers of Asian students and young men find inspiration and the path into medical school after their second year of high school. Twenty-six percent of male high school sophomores aspire to becoming a physician, and double this number apply to and enter medical school. Six percent of Asian high school sophomores have the intention of becoming a physician, and yet nearly one quarter of the applicant and matriculant pools are Asian. The emergence of the intent to become a physician in the transition from adolescence to adulthood in young men and Asian students is important to observe and may provide guidance as we look to retain a diverse group of aspirants on the path to medicine.

The split in underrepresentation and overrepresentation is even more evident in an analysis of parental education and socioeconomic considerations. The most affected group appears to be children of parents with education more than high school but without a college degree: $38 \%$ of these high school sophomores aspired to medicine, but only $6 \%$ of the matriculant pool has this level of parental education. The opposite pattern exists for young people whose parents had high educational achievement. The parents of only $9 \%$ of high school sophomores aspiring to be physicians in the study had attained a degree beyond a master's, as compared to the parents of $35 \%$ of medical school matriculants. Compounding the problem is the degree to which low socioeconomic status is related to matriculation into medical school. Students from lowincome families are far less likely to matriculate into medical school. Students from the top $20 \%$ income brackets constitute $60 \%$ of US medical students [10]. These data suggest that parental education and relevant socioeconomic factors influence whether it is possible for young people to realize their dreams to become physicians.

\section{Valuing Academic Diversity}

We value academic diversity because of the belief that interaction with individuals from varied backgrounds and life experiences provides opportunities to achieve unique and creative approaches to medical education, research, and clinical care. Indeed, research has demonstrated that diverse teams outperform homogeneous teams on innovation tasks [11].
Through such diversity, our learning environment will enable the next generation of leaders to incorporate new ways of thinking in discovery, application, integration, and teaching, as well as to better serve the needs of an increasingly diverse society. Further, it may well decrease bias, improve cultural competence in medical schools, and improve health outcomes in underserved populations.

Although the vision of achieving diversity is shared by many academic medical centers across the country, it remains an elusive goal at every level — students, resident-physicians, and faculty. Multiple factors account for our inability to achieve a substantially diverse academic medical workforce. A number of quantitative and qualitative studies clearly indicate that beyond the obvious obstacles in achieving diversity, subtle barriers such as unconscious bias and lack of diversity in leadership play a major role in our ability to recruit and retain a broadly diverse academic medical faculty pool [12-14]. Achieving at least some representation on our faculties of certain small and distinct racial and ethnic minority groups is especially important - indeed, at this time one can count, using only fingers and toes, the number of Native American or Alaskan professors in US medical schools, i.e., nine men and four women [1]. In addition, resources necessary to develop, establish, and implement faculty development and diversity programs within academic medical centers require skill sets and infrastructure investments that may not be readily identifiable or valued, especially in the current fiscally constrained economic environment that still dictates the development of academic programs.

In creating a physician workforce that more closely resembles the people and populations we serve, it is helpful to consider the effectiveness of programs that aim to reach and support young people, including ethnic minority individuals, along the path to entry into medical school [10] and biomedical science careers, e.g., outstanding special programs of the National Institute for General Medical Sciences (nigms.nih.gov). Doing so will infuse all specialties with a more diversified workforce similar to the incoming OBGYN, pediatrics, and psychiatry workforce. There have been many efforts to improve matriculation of underrepresented students into medical school at the high school, undergraduate, and postgraduate levels, for instance. One very promising approach has been the use of postbaccalaureate premedical programs to attract and prepare minority students and students whose parents had not attended college for success in medicine. In one retrospective study in the University of California (UC) system between 1999 and 2002 [15], the researchers compared participants in the UC postbaccalaureate programs with a control group of college graduates who applied to the programs but did not receive additional postbaccalaureate preparation. By 2005, about two thirds of participants and a quarter of controls matriculated into medical school. Determining whether programs are effective, and then identifying 
the "active ingredients" that allow for successful outcomes, will help educational institutions to prioritize and provide resources to enhance diversity.

We should also aim to evaluate programs that seek to improve the representation, recruitment, retention, and promotion of women and ethnic minority faculty $[2,16]$. These efforts also should inform the development of new programs and initiatives and the commitment of precious resources. Going further, quality improvement studies should be encouraged to parse out which interventions are the most valuable. The profession of medicine must redouble its commitment to invest in the development of a more diverse set of leaders to shape academic medicine for the future. Delaying this investment will only postpone our ability to address the needs of our society in this century.

\section{Diversity and Psychiatry}

It has been observed that minority individuals feel isolation, carry disproportionate responsibilities in "representing" minority perspectives within the organizations they serve, and sense a "glass ceiling" that prevents them from advancing in medicine [17]. Academic faculty members in psychiatry often have these same experiences, raising the question of the heightened challenges that minority individuals who choose psychiatry may encounter. In addition, a significant obstacle for improving diversity in psychiatry may be the problem of overcoming the general stigma of psychiatry in medical schools. It is not uncommon for medical school faculty to devalue psychiatry, either overtly or as part of the hidden curriculum [18]. Although there may be specific reasons for poor recruitment of minority individuals into psychiatry, the field itself has a significant problem with its own image, often perpetuated from within. Thus, we should be carefully and honestly considering the reasons that only 3-4 \% of American medical students overall select our field.

But there are other reasons in general for medical students choosing other specialties. One study of career choice of psychiatry compared those students who either seriously considered it as a specialty choice and those who never seriously considered the field and found that both groups were equally concerned that the profession would be stressful. Further, both groups felt negatively about psychiatry, were sensitive to the negative status of psychiatry in society, and were concerned about the relatively low earning potential of psychiatry and the possible impact of healthcare system changes on psychiatric practice [19]. These factors may be even more of a disincentive for underrepresented minority individuals, many of whom appreciate personally the issues of stress, stigma, marginalization, and low income. It may be that by improving the image, the incomes, and the career satisfaction of practicing psychiatrists, there may be a significant improvement in recruitment of minority students - many of whom wish to take care of the underrepresented populations in the community and in academic settings.

In general, we have much to do to correct the devaluation of psychiatry within medicine, which not only affects medical students but also residents and psychiatric faculty members. Programs that support minority faculty members and diversity initiatives in psychiatry should be studied and expanded where effective [20-24].

\section{Conclusions}

If we are intent on creating a physician workforce that more closely resembles the diverse population of our country, we must reach young people from different backgrounds to support them along the path to a career in medicine. And if we are intent on academic medicine resembling our broader society, we must do much to keep them on this path. Moreover, we should look not just to ethnic minority students from the highly educated middle and upper middle classes, but to low-income minority high school and college students with the requisite abilities to succeed but without the social or economic resources or encouragement to do so [25]. Thus, ethnic status, income, and gender, as well as other factors related to personal experiences and identity, should count in diversifying the workforce. An increased diversity of personal experiences and identities in the workforce will, we suggest, reduce disparities, promote a diversity of ideas, and assist in solving important public health problems.

Efforts to support diversity in academic medical centers must be encouraged and actively promoted if we are to provide leaders and role models for the next generation of an academic medical workforce that will serve the populace of the future. Although academic leadership may value such efforts in a theoretical sense, the implementation and sustainability of diversity programs may be difficult to achieve, because the results are not always immediately apparent. Support for these efforts must come from the very top levels of the leadership. Reaching into an earlier period of personal and professional development will help us to establish a secure and supportive path to medicine for, as yet, underrepresented individuals. Then, we together will have the responsibility and the joy of facilitating the professional development of these very special early "career" colleagues as they find their calling in medicine.

Disclosure On behalf of all authors, the corresponding author states that there is no conflict of interest. 


\section{References}

1. Association of American Medical Colleges. Faculty roster: 2013. Available at http://www.aamc.org/data/facultyroster/. Accessed 17 May 2014.

2. Guevara JP, Adanga E, Avakame E, Carthon MB. Minority development programs and underrepresented minority faculty representation at US medical schools. JAMA. 2013;310:2297-304.

3. United States Census Bureau. The Black Population: 2010, May 2011. Available at http://www.census.gov/2010census/. Accessed 6 May 2014.

4. United States Census Bureau. The Hispanic Population: 2010, May 2011. Available at http://www.census.gov/2010census/. Accessed 6 May 2014

5. United States Census Bureau. U.S. Census Bureau Projections Show a Slower Growing, Older, More Diverse Nation a Half Century from Now. Available at http://www.census.gov/newsroom/releases/ archives/population/cb12-243.html. Accessed 17 May 2014.

6. Cooper LA, Powe NR: Disparities in patient experiences, health care processes, and outcomes: the role of the patient-provider: racial, ethnic, and language concordance, The Commonwealth Fund, July 2004. Available at www.cmwf.org. Accessed 17 May 2014.

7. Cooper LA, Roter DL, Johnson RL, Ford DE, et al. Patient-centered communication, ratings of care, and concordance of patient and physician race. Ann Intern Med. 2003;139:907-15.

8. Green AR, Carney DR, Pallin DJ, et al. Implicit bias among physicians and its prediction of thrombolysis decisions for Black and White patients. J Gen Intern Med. 2007;22:1231-8.

9. American Medical Association: AMA Physician Masterfile. Available at http://www.ama-assn.org/ama/pub/about-ama/ physician-data-resources/physician-masterfile.page?. Accessed 15 May 2014

10. Analysis in brief, Volume 14, Number 3, March 2014. An analysis of the medical school pipeline: a high school aspirant and enrollment view.

11. Page S: The difference: how the power of diversity creates better groups, firms, schools, and societies 2008: Princeton University Press.

12. Cejka MA, Eagly AH. Gender stereotypic images correspond to the segregation of employment. Pers Soc Psychol Bull. 1999;25:413-23.
13. Fang D, Moy E, Collburn L, et al. Racial and ethnic disparities in faculty promotion in academic medicine. JAMA. 2000;284(9):108592

14. Price EG, Gozu A, Kern DE, et al. The role of cultural diversity climate in recruitment, promotion, and retention of faculty in academic medicine. J Gen Intern Med. 2005;20(7):565-71.

15. Grumbach K, Chen E. Effectiveness of University of California postbaccalaureate premedical programs in increasing medical school matriculation for minority and disadvantaged students. JAMA. 2006;9:1079-85.

16. Association of American Medical Colleges: Diversity in Medical Education, Facts and Figures 2012. Available at www.aamc.org/ publications. Accessed 27 May 2014.

17. Cohen JJ. Time to shatter the glass ceiling for minority faculty. JAMA. 1998;280(9):821-2.

18. Stoudemire A. Quo vadis psychiatry? Problems and potential for the future of medical education in psychiatry. Psychosomatics. 2000;41(3):204-9.

19. Cutler JI, Alspectgor SL, Harding KJ, Wright LL, Graham MJ. Medical students' perceptions of psychiatry as a career choice. Acad Psychiatry. 2006;30:144-9.

20. Eaglan RH, Arnold L, Girotti JA, et al. The scope and variety of combined baccalaureate-MD programs in the United States. Acad Med. 2012;87:1600-8.

21. Peek ME, Kim KE, Johnson JK, Vela MB. "URM candidates are encouraged to apply": a national survey to identify effective strategies to enhance racial and ethnic faculty diversity in academic departments of medicine. Acad Med. 2013;88:405-12.

22. Harris TB, Mian A, Lomax JW, et al. The Texas regional psychiatry minority mentor network: a regional effort to increase psychiatry's workforce diversity. Acad Psychiatry. 2012;36:60-3.

23. Wiitzkin H, Yager J, Parker T, et al. Mentoring partnerships for minority faculty and graduate students in mental health services research. Acad Psychiatry. 2006;30:205-17.

24. Lim RF, Luo JS, Suo S, et al. Diversity initiatives in academic psychiatry: applying cultural competence. Acad Psychiatry. 2008;32:283-90.

25. Johnson J, Bozeman B. Perspective: adopting an asset bundle model to support and advance minority students' careers in academic medicine and the scientific pipeline. Acad Med. 2012;87:1488-95. 